\title{
Supramolecular Structures of Oil Systems as the Key to Regulation of Oil Behavior
}

\author{
Tukhvatullina AZ ${ }^{1 *}$, Barskaya EE ${ }^{1}$, Kouryakov VN² , Ganeeva YM ${ }^{1}$, Yusupova TN ${ }^{1}$ and Romanov GV ${ }^{1}$
}

${ }^{1}$ AE Arbuzov Institute of Organic and Physical Chemistry of Kazan Scientific Center of Russian Academy of Sciences, Kazan, Russia

${ }^{2}$ Oil and Gas Research Institute of Russian Academy of Sciences, Moscow, Russia

\begin{abstract}
The paper is devoted to investigation of supramolecular structures formed by high-molecular components of oil - asphaltenes and waxes. Petroleum asphaltenes that are characterized by their ability to self-organization can be considered as a polydisperse system. The aggregation of A1and A2 asphaltenes both in toluene solution and in diluted heavy oils was studied by dynamic light scattering technique. The stabilizing role of resins was confirmed. Due to the fact that the supramolecular structures in oils can be also formed by high molecular microcrystalline waxes, their influence as well as A1 and A2 asphaltenes on wax crystallization process was evaluated using optical microscopy. The effect of the different molecular structures of asphaltenes (A1 and A2) on the rheological properties of crude oils was also observed. Self-organization of asphaltenes directly in heavy high-viscosity oils with high content of resins was investigated by varying the ratios oil:precipitant. It was shown that extremely stable supramolecular structures in heavy oils had been formed. The influence of ultrasonic action for the destruction of stable supramolecular structures and the reduction of oil viscosity were considered.

Also petroleum asphaltenes can be the indicators of many processes that occur in the reservoir. We have shown the possibility of using the gradient of asphaltenes, as well as their structure, to confirm the influx of deep light hydrocarbons in carbonate reservoirs. Thus, all obtained results of investigation of structure formation processes will let regulate the macroscopic properties of heavy oils in the future and identify the processes occurring in the reservoir.
\end{abstract}

Keywords: Supramolecular structures; Disperse system; Asphaltenes; Asphaltene aggregation

\section{Introduction}

According to the modern concepts, the oil is a complex multicomponent disperse system. The theory of oil disperse systems [1-4] supposes that the liquid phase compounds are oriented around the supramolecular structures forming solvation layers. The disperse particles are characterized by a complex structure in this case: the core formed by high-molecular components of oil (asphaltenes, microcrystalline waxes) and the solvation shell surrounding the core and consisting of resins. The disperse media in such model is presented by hydrocarbons of oils. At present, the focused attention is paid to the most high-molecular-mass, polar oil components-asphaltenes [5-30]. Asphaltenes are characterized by their ability to self-organization (or self assembly), and therefore the presence of a hierarchy of structures in oil media: molecules-nanoaggregates-clusters of nanoaggregates [5-9] (Figure 1). That is why asphaltenes can be attributed to the objects of supramolecular chemistry.

Petroleum asphaltenes can be considered as a complex polydisperse system of molecules in which subcomponents with significantly different characteristics can be distinguished as the result of the fractionation procedure [27]. At present, two asphaltene molecule types-"continental" (A1 fraction) and "archipelago" (A2 fraction) are adopted as the basic models (Figure 2) [10-15,26]. It should be noted that in crude oils asphaltene aggregates of both types exist in various proportions. As the asphaltene fractionation procedure is rather time and labor consuming, it is not possible to isolate absolutely pure fractions of asphaltenes but concentrates enriched in asphaltenes of one or another structure [26,27].

The main difference between A1 and A2 asphaltenes is their structure determining different ability to aggregate. A1 asphaltene molecules even at low concentrations form aggregates, followed by the introduction of A2 asphaltene molecules into these units [13]. Thus, A1 and A2 asphaltene molecules in oils form a disperse phase where the core is presented by stacks of the "continental" type of asphaltenes and the periphery rich in the "archipelago" type of asphaltenes $[14,15]$.

In recent scientific literature, there are many studies on the selforganization of asphaltenes in solutions of solvents [28-30]. However, the study of the asphaltenes behavior directly in the oil system is of a much greater interest, since regularities obtained in solutions do not reflect the nature and completeness of the processes that occur in real oils. Therefore we have studied aggregation of A1 and A2 asphaltenes both in toluene solution and in diluted heavy oils with concentrations that are close to real oils by dynamic light scattering technique. The concentration of solutions is also limited by the sensitivity of instruments. The effect of the different molecular structures of asphaltenes was also shown by measuring rheological properties of crude oils.

*Corresponding author: Tukhvatullina AZ, AE Arbuzov Institute of Organic and Physical Chemistry of Kazan Scientific Center of Russian Academy of Sciences, Kazan, Russia, E-mail: tukhvatullina@iopc.ru, talinza@mail.ru

Received July 09, 2013; Accepted August 24, 2013; Published September 02 2013

Citation: Tukhvatullina AZ, Barskaya EE, Kouryakov VN, Ganeeva YM, Yusupova TN, et al. (2013) Supramolecular Structures of Oil Systems as the Key to Regulation of Oil Behavior. J Pet Environ Biotechnol 4: 152. doi:10.4172/2157-7463.1000152

Copyright: () 2013 Tukhvatullina AZ, et al. This is an open-access article distributed under the terms of the Creative Commons Attribution License, which permits unrestricted use, distribution, and reproduction in any medium, provided the original author and source are credited. 
Citation: Tukhvatullina AZ, Barskaya EE, Kouryakov VN, Ganeeva YM, Yusupova TN, et al. (2013) Supramolecular Structures of Oil Systems as the Key to Regulation of Oil Behavior. J Pet Environ Biotechnol 4: 152. doi:10.4172/2157-7463.1000152

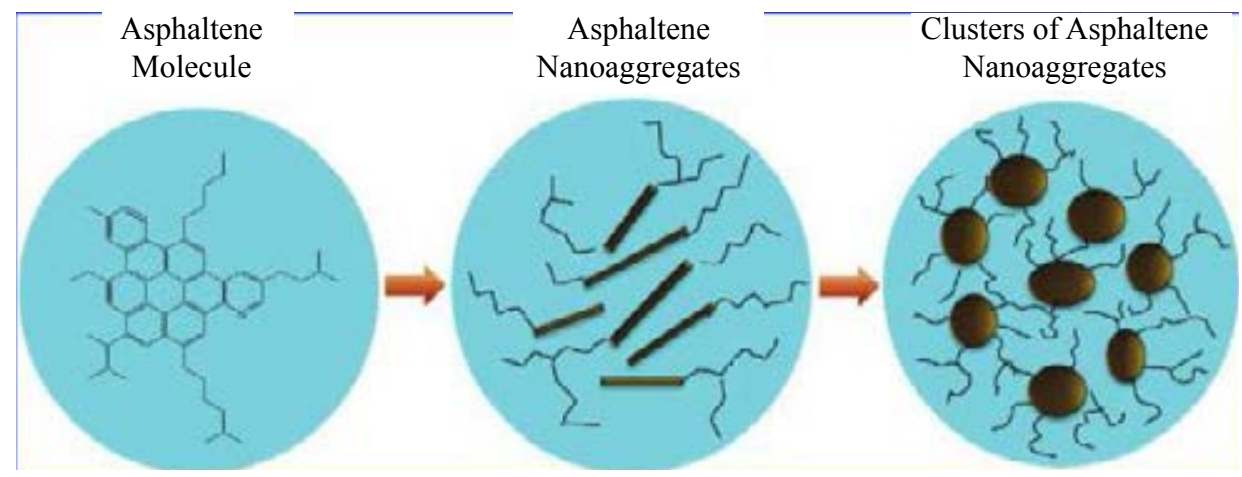

Figure 1: A modified Yen model (or Yen-Mullins model of asphaltenes) [5].
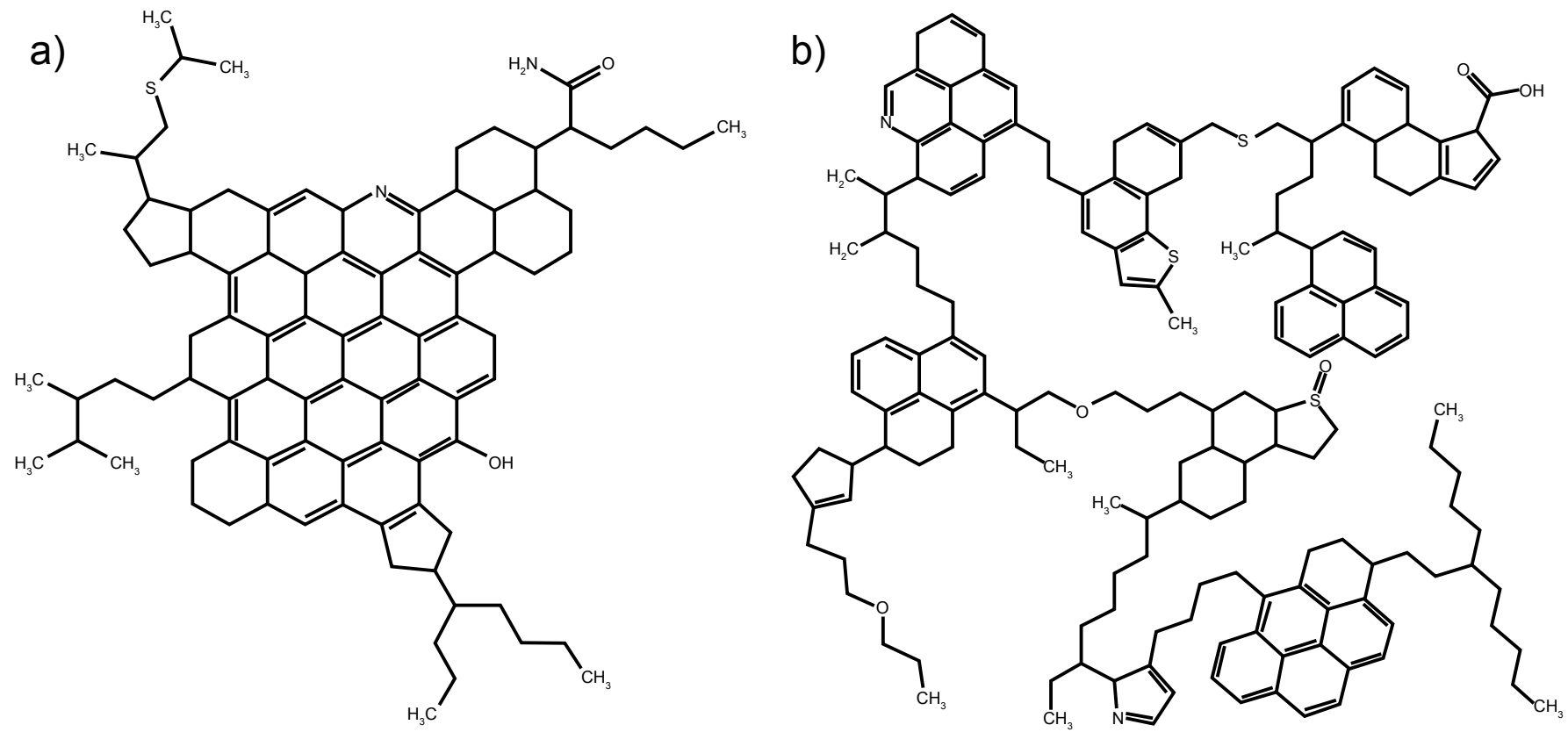

Figure 2: Model of asphaltene molecules: a) the "continental" type, and b) the "archipelago" type [11].

\section{Method}

The objects of study were heavy high-viscosity crude oils from carbonates of the Akanskoe field of Tatarstan Republic, Russia. It should be noted that oil samples from one of the wells have been specially selected from the upper (top) and bottom parts of the reservoir [31].

Asphaltenes under investigation were precipitated from the crude oils with a 40 -fold excess of nhexane followed by separation into three asphaltene fractions according to their ability to form the aggregates [12]. It is assumed that the first asphaltene fraction that is precipitated under the minimal addition of the precipitant, is a concentrate of A1 asphaltene molecules (the "continental" type), while the third fraction, which remains in solution, presented by A2 asphaltene molecules (the "archipelago" type). The intermediate fraction is a mixture of A1 and A2 asphaltene molecules [12].

The asphaltene aggregation was studied by photon correlation spectroscopy (dynamic light scattering). Toluene-heptane system used is a widely accepted model system for studying the properties of the asphaltenes [32-34].
The photomicrographs of oils and model systems were obtained using Olympus CX41 microscope with a digital photomicroscopy system based on Olympus E420 digital camera and ImageScope M software. Photomicrographs were obtained in transmitted light between crossed polaroids at 100-400 x magnifications.

Thermal analysis (TA) of asphaltenes and their fractions was performed with a MOM Q-1500D differential thermal analyzer (Hungary) over the temperature range of $20-1000^{\circ} \mathrm{C}$ at an oven heating rate of $10^{\circ} \mathrm{C} / \mathrm{min}$. The chemical composition of asphaltenes was characterized by the mass loss values at different stages of thermal oxidative degradation $\left(20-410^{\circ} \mathrm{C}, 410-530^{\circ} \mathrm{C}\right.$ and $\left.530-700^{\circ} \mathrm{C}\right)$ [35].

The presence of waxes in asphaltenes was fixed by hightemperature gas-liquid chromatography technique (GLC) on a PerkinElmer chromatograph with a flame-ionization detector in the mode of temperature programming from 20 to $360^{\circ} \mathrm{C}$.

Electron Paramagnetic Resonance (EPR) spectrum of asphaltenes and their fractions were obtained at room temperature with a spectrometer type SE/X-2544. The content of stable free radicals (IR) 
Citation: Tukhvatullina AZ, Barskaya EE, Kouryakov VN, Ganeeva YM, Yusupova TN, et al. (2013) Supramolecular Structures of Oil Systems as the Key to Regulation of Oil Behavior. J Pet Environ Biotechnol 4: 152. doi:10.4172/2157-7463.1000152

Page 3 of 8

was estimated by the amplitude of a single line in the center of the EPR spectrum. Complex viscosity measurements were carried out using Rheotest RN4.1 (MessgeräteMedingen $\mathrm{GmbH}$ ) over temperature range $20-80^{\circ} \mathrm{C}$

Oil processing by ultrasound was performed using an ultrasonic apparatus "Alena" [36] with the frequency of $22 \mathrm{kHz}$. The intensity of ultrasound was regulated from 10 to $100 \mathrm{~W} / \mathrm{cm}^{2}$. Exposure time was from 1.5 to 20 minutes [37].

\section{Results}

One of the most promising techniques to monitor in real time the kinetics of asphaltene aggregation and measure a changing size of the aggregates is the dynamic light scattering (DLS) [32-34]. It allows determining the value of the threshold concentration of precipitant that characterizes so called "zero rate of aggregation" -the stability threshold of system. The aggregation of initial asphaltenes and their fractions were studied in toluene solutions, diluted heavy oils and model systems by dynamic light scattering technique. Initial asphaltenes were obtained from the crude oils from the top and bottom parts of the reservoir. In order to identify the role of asphaltene molecules-A1 and A2, the model mixtures from deasphalted oil with different asphaltene fractions were prepared.

The kinetics of asphaltene aggregation in toluene solutions with asphaltene concentration of $0.1 \mathrm{~g} / \mathrm{l}$ is described by the diffusion-limited mechanism, i.e. aggregation rate is mainly determined by diffusion of particles. The changes in the aggregates sizes are shown in Figure 3. The rate of aggregation increases significantly with increasing of precipitating agent volume. For each volume of precipitant aggregate, size increases with time according to a power law.

The values of the stability threshold were determined for the majority of solutions of asphaltenes and their fractions with a concentration of $0.1 \mathrm{~g} / \mathrm{l}$ and $5 \mathrm{~g} / \mathrm{l}$ (Table 1). The solutions with the concentration of asphaltenes $5 \mathrm{~g} / \mathrm{l}$ in toluene were investigated at installation with the Infrared (IR) laser. The wavelength of IR laser was $980 \mathrm{~nm}$; the wavelength of red laser was $632 \mathrm{~nm}$. In the solutions of A2 asphaltenes with concentration of $0.1 \mathrm{~g} / \mathrm{l}$ the formation of aggregates was not observed up to a precipitant concentration of $90 \%$ (by weight). The aggregation of A2 asphaltenes was fixed only for solutions with a concentration of $5 \mathrm{~g} / \mathrm{l}$ and to a much lesser extent than in solutions of A1 asphaltenes even with a concentration of $0.1 \mathrm{~g} / \mathrm{l}$.

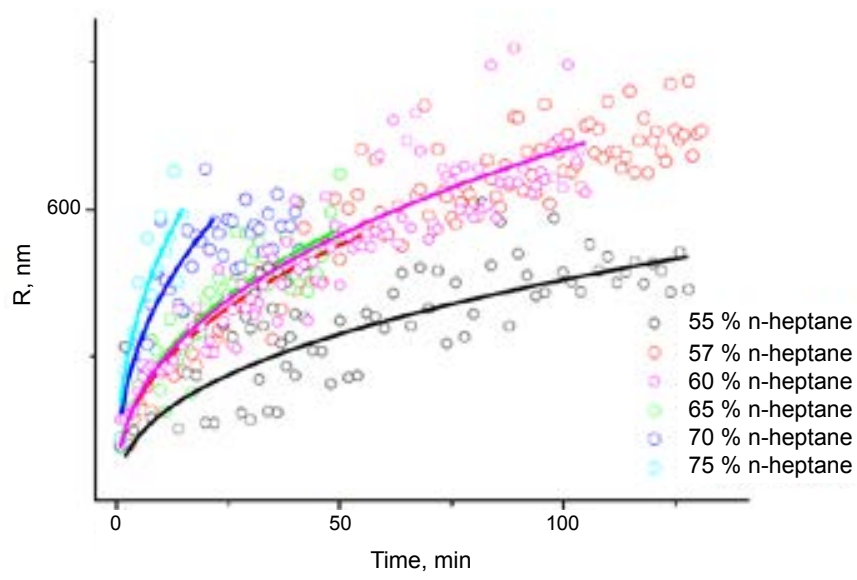

Figure 3: Aggregation kinetics of $0.1 \mathrm{~g} / \mathrm{l}$ asphaltene solution for various heptane volumes.

$\mathrm{R}$-the size of aggregates, $\mathrm{nm}$

\begin{tabular}{|c|c|c|c|}
\hline No. & Sample & $\begin{array}{c}\text { The threshold concentration } \\
\text { of heptane,\% wt. (for } \\
\text { 0.1g/l asphaltenes/ } \\
\text { toluenesolutions) }\end{array}$ & $\begin{array}{c}\text { The threshold } \\
\text { concentration of } \\
\text { heptane, \% wt. (for } 5 \mathrm{~g} / \mathrm{l} \\
\text { asphaltenes/toluene } \\
\text { solutions) }\end{array}$ \\
\hline 1 & $\begin{array}{c}\text { Initial asphaltenes } \\
\text { (top part) }\end{array}$ & 46 & 40 \\
\hline 2 & $\begin{array}{c}\text { Initial asphaltenes } \\
\text { (bottom part) }\end{array}$ & 48 & 46.5 \\
\hline 3 & $\begin{array}{c}\text { Asphaltenes A1 (top } \\
\text { part) }\end{array}$ & 28 & 25 \\
\hline 4 & $\begin{array}{c}\text { Asphaltenes A1 } \\
\text { (bottom part) }\end{array}$ & - & 20.2 \\
\hline 5 & $\begin{array}{c}\text { Asphaltenes A2 (top } \\
\text { part) }\end{array}$ & - & 69 \\
\hline 6 & $\begin{array}{c}\text { Asphaltenes A2 } \\
\text { (bottom part) }\end{array}$ & & 55 \\
\hline
\end{tabular}

Table 1: The threshold concentrations of heptane for $0.1 \mathrm{~g} / \mathrm{l}$ and $5 \mathrm{~g} / \mathrm{l}$ solutions of asphaltenes and their fractions in toluene.

In toluene solutions with a low asphaltene concentration the stability threshold of asphaltenes of oils from top and bottom parts of the carbonate reservoir is almost the same despite the different content of $\mathrm{A} 1$ and $\mathrm{A} 2$ fractions (which differ by their stability) in initial asphaltenes. Initial asphaltenes of oil from the bottom of the reservoir are enriched in A1 asphaltenes (64.6\%) and depleted in A2 asphaltenes (8.1\%) while asphaltenes from the top of the reservoir contains less A1 asphaltenes (49.4\%) and twice the amount of A2 asphaltenes (15.7\%) [31]. The rest part of asphaltenes is presented by the intermediate fraction-a mixture of $\mathrm{A} 1$ and $\mathrm{A} 2$ asphaltenes [12]. This may be stipulated by the fact that asphaltenes in both cases exist only as nanoaggregates in solutions with a low asphaltene concentration.

Further research was devoted to investigation of asphaltene aggregation in diluted heavy oils as well as model systems with the concentration of $125 \mathrm{~g} / \mathrm{l}$ by weight in toluene. Model systems are the mixtures of deasphalted oils (maltenes) supplemented with 5\%(15\%) of different asphaltene fractions (A1 or A2). Solutions with the concentration of $500 \mathrm{~g} / \mathrm{l}$ by weight in toluene were also prepared for crude oils (ratio 1:1 by weight). The threshold stability of oil systems was defined by titration.

Thus, the method of dynamic light scattering showed a greater capacity of asphaltenes enriched in A1 molecules for aggregation in the oil systems. With increasing concentration of $\mathrm{A} 1$ asphaltenes from 5 to $15 \%$ the threshold stability is not so much reduced as it could be expected, while the viscosity increases from $1020 \mathrm{mPs}$-s to $7185 \mathrm{mPs}-\mathrm{s}$ (the shear rate was 11s-1.).

Probably, the increasing concentration of A1 asphaltenes leads to the formation of coagulation structures which impede their further additional aggregation of asphaltenes.

An interesting fact is that the stability threshold of crude oils is only slightly dependent on the volume of added toluene (Table 2). This suggests a slight influence of the solvent proportion (1:1 or 1:4) on the process of asphaltene aggregation, particularly the threshold concentration of heptane, despite the fact that viscosity changes are essential.

It was found that aggregation of asphaltenes and A1 and A2 fractions in toluene solution has a higher rate in comparison with the aggregation in diluted oils and model systems (Table 2), confirming the stabilizing role of components of oil systems. According to the literature [19-22], resins are the stabilization factor of asphaltenes in 
Citation: Tukhvatullina AZ, Barskaya EE, Kouryakov VN, Ganeeva YM, Yusupova TN, et al. (2013) Supramolecular Structures of Oil Systems as the Key to Regulation of Oil Behavior. J Pet Environ Biotechnol 4: 152. doi:10.4172/2157-7463.1000152

\begin{tabular}{|c|c|c|c|}
\hline No. & Sample & $\begin{array}{c}\text { The concentration of } \\
\text { solution, g/l }\end{array}$ & $\begin{array}{c}\text { The threshold } \\
\text { concentration of } \\
\text { n-heptane, \% wt. }\end{array}$ \\
\hline 1 & Oil (top part) & 500 & 60.8 \\
\hline 2 & Oil (bottom part) & 500 & 57.5 \\
\hline 3 & Oil (top part) & 125 & 61.4 \\
\hline 4 & Oil (bottom part) & 125 & 59.7 \\
\hline 5 & $\begin{array}{c}\text { Maltenes + A1 asphaltenes } \\
\text { (5\%) (top part) }\end{array}$ & 125 & 48.1 \\
\hline 6 & $\begin{array}{c}\text { Maltenes + A1 asphaltenes } \\
(15 \%) \text { top part) }\end{array}$ & 125 & 43.3 \\
\hline 7 & $\begin{array}{c}\text { Maltenes + A2 asphaltenes } \\
\text { (5\%) (top part) }\end{array}$ & 125 & 77.4 \\
\hline 8 & $\begin{array}{c}\text { Maltenes + A1 asphaltenes } \\
\text { (5\%) (bottom part) }\end{array}$ & 125 & 44.9 \\
\hline 9 & $\begin{array}{c}\text { Maltenes + A2 asphaltenes } \\
(5 \%) \text { (bottom part) }\end{array}$ & 125 & 69.5 \\
\hline
\end{tabular}

Table 2: The threshold concentration of heptane for solutions of oils and model systems.

crude oils, due to their peptizing action. However, there is virtually no experimental data quantifying the role of resins.

To study the effect of resins on the stability of the hydrocarbon fluids the kinetics of asphaltene aggregation in toluene-heptane system was investigated during addition of resins with three different concentrations: $0.2 \mathrm{~g} / \mathrm{l}, 0.6 \mathrm{~g} / \mathrm{l}$ and $1 \mathrm{~g} / \mathrm{l}$. The concentration of asphaltenes in all cases was $0.1 \mathrm{~g} / \mathrm{l}$. For ease of comparison, the kinetics of growth of aggregates was measured at concentrations of $n$-heptane equal to $60,65,70,75$ and 80 weight percent. In all cases the same power-law dependence of the radius on time as that in the absence of resins was observed, i.e. for solutions with asphaltene concentration of $0.1 \mathrm{~g} / \mathrm{l}$ the diffusion limited aggregation is observed.

Figure 4 shows the measurement results of the radius of asphaltene aggregates in the solutions containing different amounts of resins at a fixed (70 weight percent) concentration of $n$-heptane. The results obtained for other $n$-heptane concentrations $(60,65,75$ and 80 weight percent) are quite similar.

It was shown that an increase in resins concentration leads to the decrease of the rate of aggregates growth as well as their amount. Furthermore, the introduction of resins into the asphaltene solution increases the threshold concentration of $n$-heptane. In the field of hydrocarbon solutions instability with respect to precipitation of heavy fractions, addition of resins leads to a significant slowdown in the aggregation reaction. Thus, the stabilizing role of resins is substantiated.

Due to the fact that the supramolecular structures in oils can be also formed by high molecular microcrystalline waxes, their influence as well as influence of asphaltene fractions on wax crystallization process was evaluated using optical microscopy. Figure 5 shows photomicrographs of oils and model systems. Observation between crossed polaroids allows to characterize the distribution and size of the wax crystallites in the samples.

Maltenes (deasphalted oil) from the oil of the top part of the reservoir contain wax crystallites that are large enough compared with the original oil (Figure 5). This can be explained by the procedure of maltenes separation resulting in removing gasoline fractions that serve as a solvent of waxes, and asphaltenes inhibiting the wax crystallization process from crude oils. In maltenes from the oil of the bottom of the reservoir the crystal growth is not observed due to the fact that the oil is enriched in microcrystalline waxes with carbon atoms number from 40 to 60 (C40-C60), which are likely to disperse macrocrystalline waxes (C16-C40) [31]. The content of microcrystalline waxes in the oil from the top of the reservoir is substantially lower but the content of macrocrystalline waxes is higher. The dispersion of the crystalline

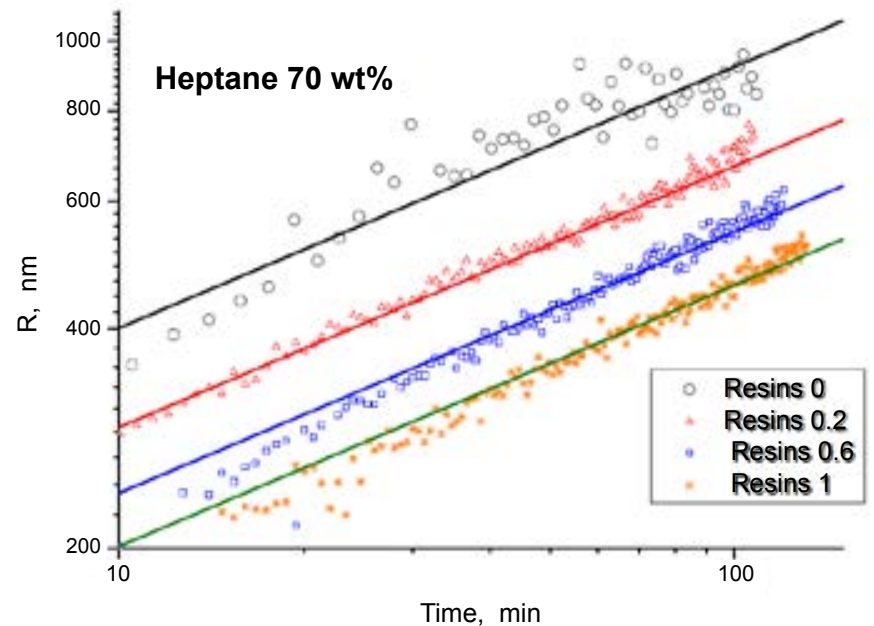

Figure 4: Aggregation kinetics of asphaltene solution for various resins amount.

R-the size of aggregates, $\mathrm{nm}$
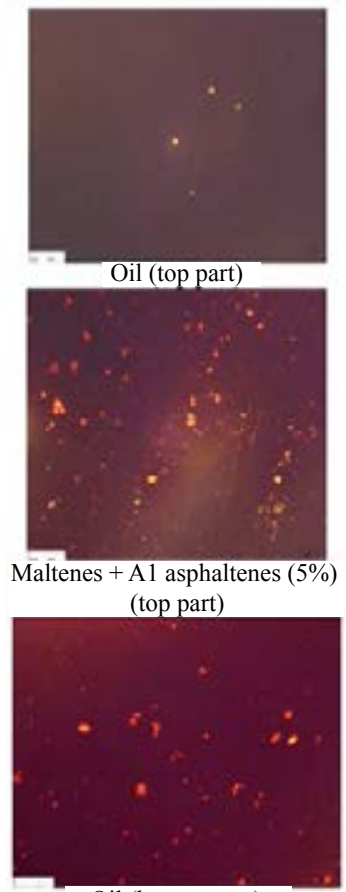

Oil (bottom part)

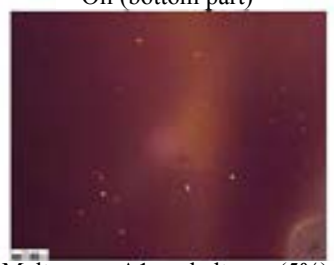

Maltenes + A1 asphaltenes $(5 \%)$ (bottom part)

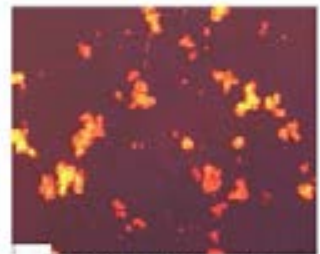

Maltenes (top part)

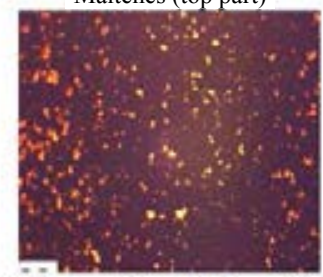

Maltenes $+\mathrm{A} 2$ asphaltenes $(5 \%)$

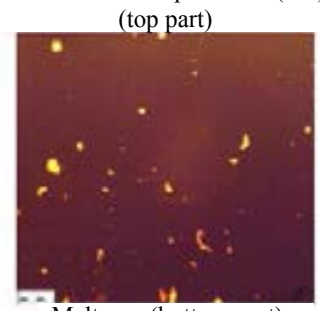

Maltenes (bottom part)

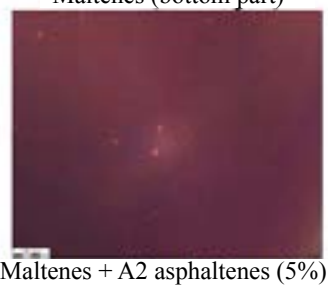

(bottom part)
Figure 5: Photomicrographs of oils and model systems obtained by optical microscope. 
Citation: Tukhvatullina AZ, Barskaya EE, Kouryakov VN, Ganeeva YM, Yusupova TN, et al. (2013) Supramolecular Structures of Oil Systems as the Key to Regulation of Oil Behavior. J Pet Environ Biotechnol 4: 152. doi:10.4172/2157-7463.1000152

phase can also be observed when asphaltenes (A1 and A2 fractions) are added to maltenes. This finding confirms the role of asphaltenes as the inhibitors of wax crystallization [23,24]. Moreover, the ntroduction of A2 asphaltenes in maltenes leads to more intensive dispersion.

Self-organization of asphaltenes directly in heavy high-viscosity oils with high content of resins was investigated by varying the ratios oil:precipitant [38]. It was found that the quantitative content of precipitating asphaltene aggregates in heavy oils from carbonate reservoirs is not dependent on the concentration of the first portion of the precipitant-n-alkane $(10,20,30 \%)$ (Table 3). The thermal analysis data $\left(\Delta \mathrm{m}^{3}\right.$-mass loss values at very high temperatures-530-700 $\left.{ }^{\circ} \mathrm{C}\right)[35]$ and EPR spectroscopy data (content of stable free radicals) showed that a decrease in the share of the first portion of the precipitant leads to reducing the content of polycondensed 8 aromatic structures in the asphaltene aggregates (Figures 6 and 7) due to co-precipitation of waxes according to GLC data (Figure 8). The purest separation of asphaltenes is observed during a conventional technique of asphaltene precipitation in a 40 -fold excess of $n$-alkane.

The effective technique to fix the formation/destruction of supramolecular structures in oils is rheology method. The capacity of high-viscosity oils from carbonate reservoirs to structure forming at higher temperatures was shown. In order to identify the effect of asphaltene molecules-propagators (A1) and terminators (A2) of aggregation on the oil structure, the study of model mixtures from deasphalted oil with different asphaltene fractions was carried out.

The phase transition temperatures were identified (Figure 9). At low temperatures $\left(20-30^{\circ} \mathrm{C}\right)$ according to the high values of the activation energy of viscous flow oil systems are characterized by coagulation structure (so called the bound-dispersed state). Since investigated oil systems contain waxes, the phase transition at $30-60^{\circ} \mathrm{C}$ can be attributed to the process of destruction of the crystalline phase.

\begin{tabular}{|c|c|c|c|c|c|c|c|c|c|c|}
\hline \multirow{3}{*}{ Sample } & \multicolumn{10}{|c|}{ The ratio oil:precipitant upon addition the first portion of the precipitant } \\
\hline & \multirow{2}{*}{ 1:40 } & \multicolumn{3}{|c|}{$1: 30$} & \multicolumn{3}{|c|}{$1: 20$} & \multicolumn{3}{|c|}{$1: 10$} \\
\hline & & I fr., \% & II fr., \% & $\Sigma, \%$ & I fr., \% & II fr., \% & $\Sigma, \%$ & I fr., \% & II fr., \% & $\Sigma, \%$ \\
\hline Crude oil & $11.0-12.0$ & 11.9 & 0.1 & 12 & 12 & 0.2 & 12.2 & 11.5 & 0.5 & 12 \\
\hline
\end{tabular}

Table 3: The content of asphaltenes obtained from crude oils by two-step precipitation and standard precipitation techniques.

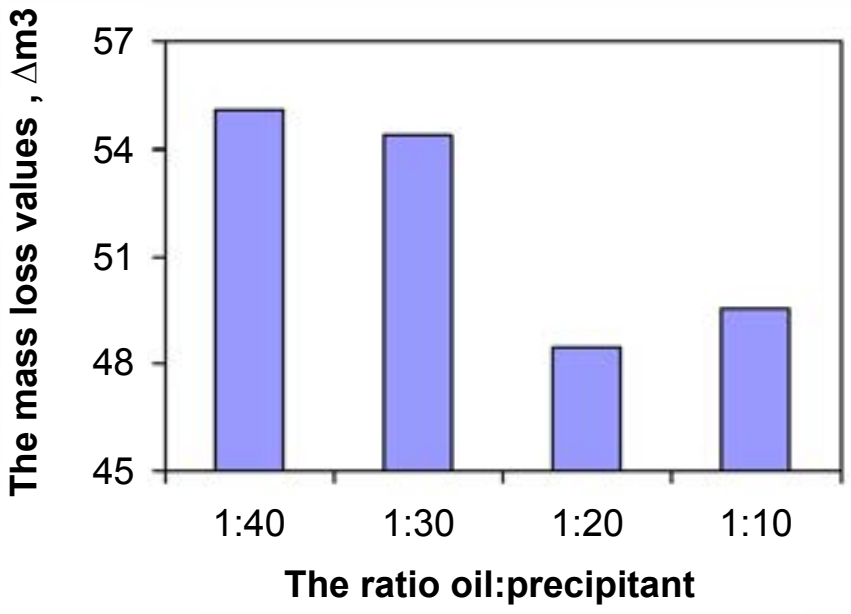

Figure 6: The thermal analysis data of the first asphaltene fractions.

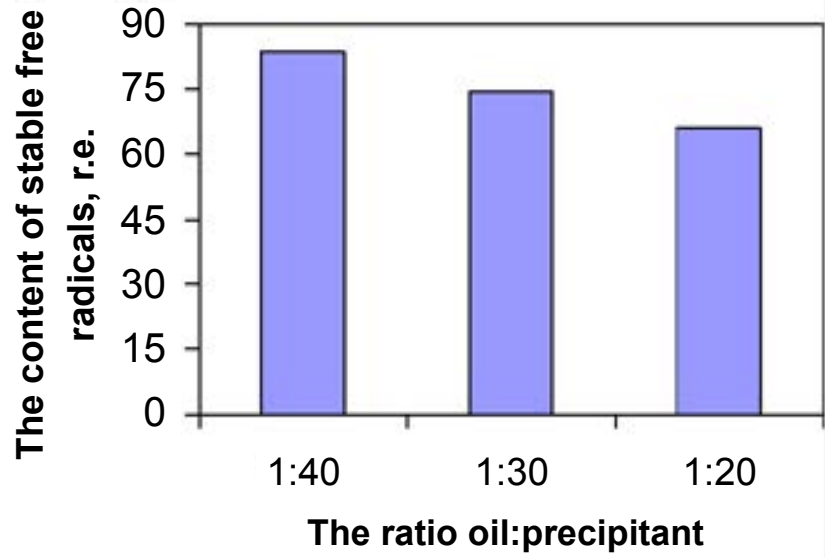

Figure 7: The EPR spectroscopy data of the first asphaltene fractions. 


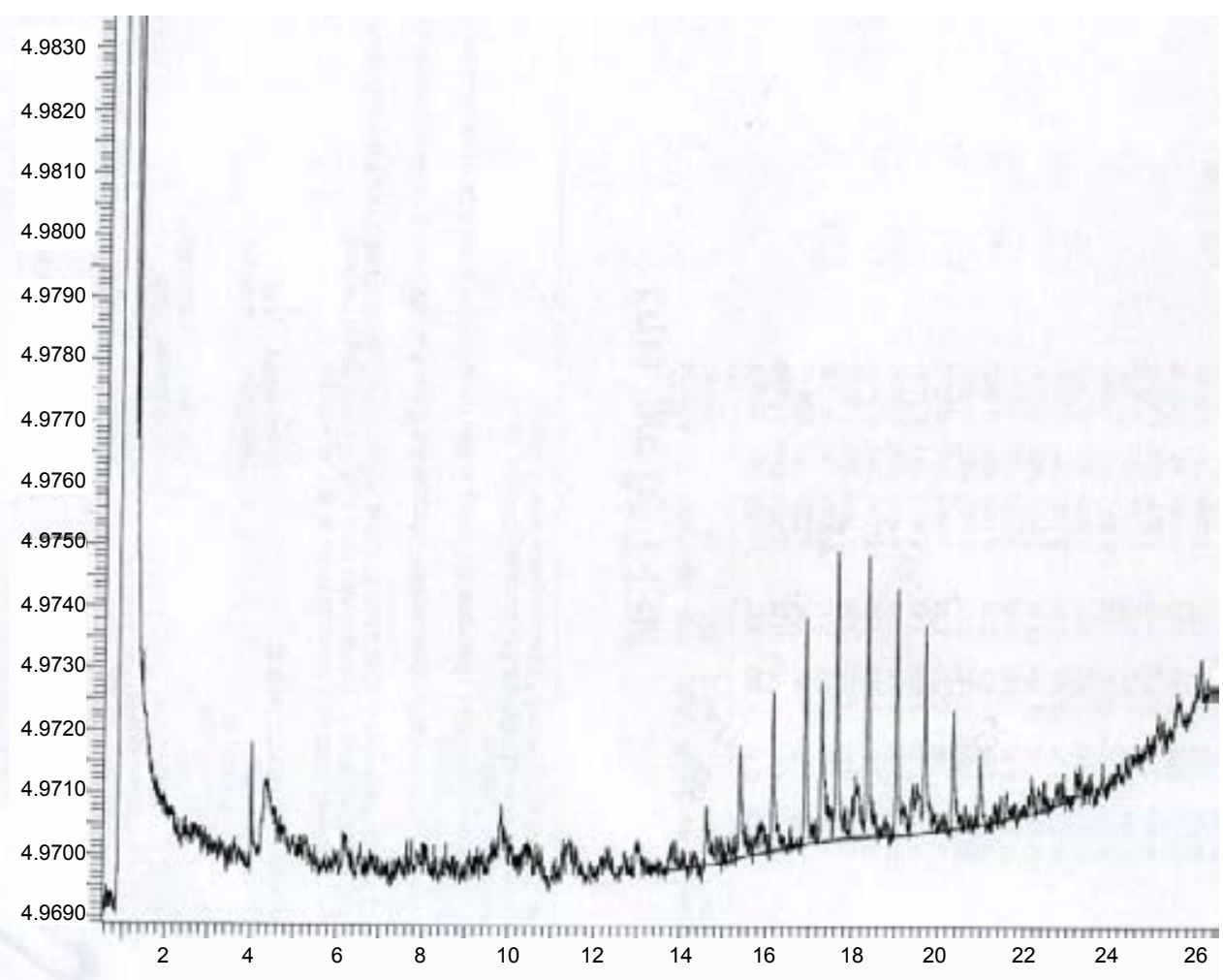

(a)

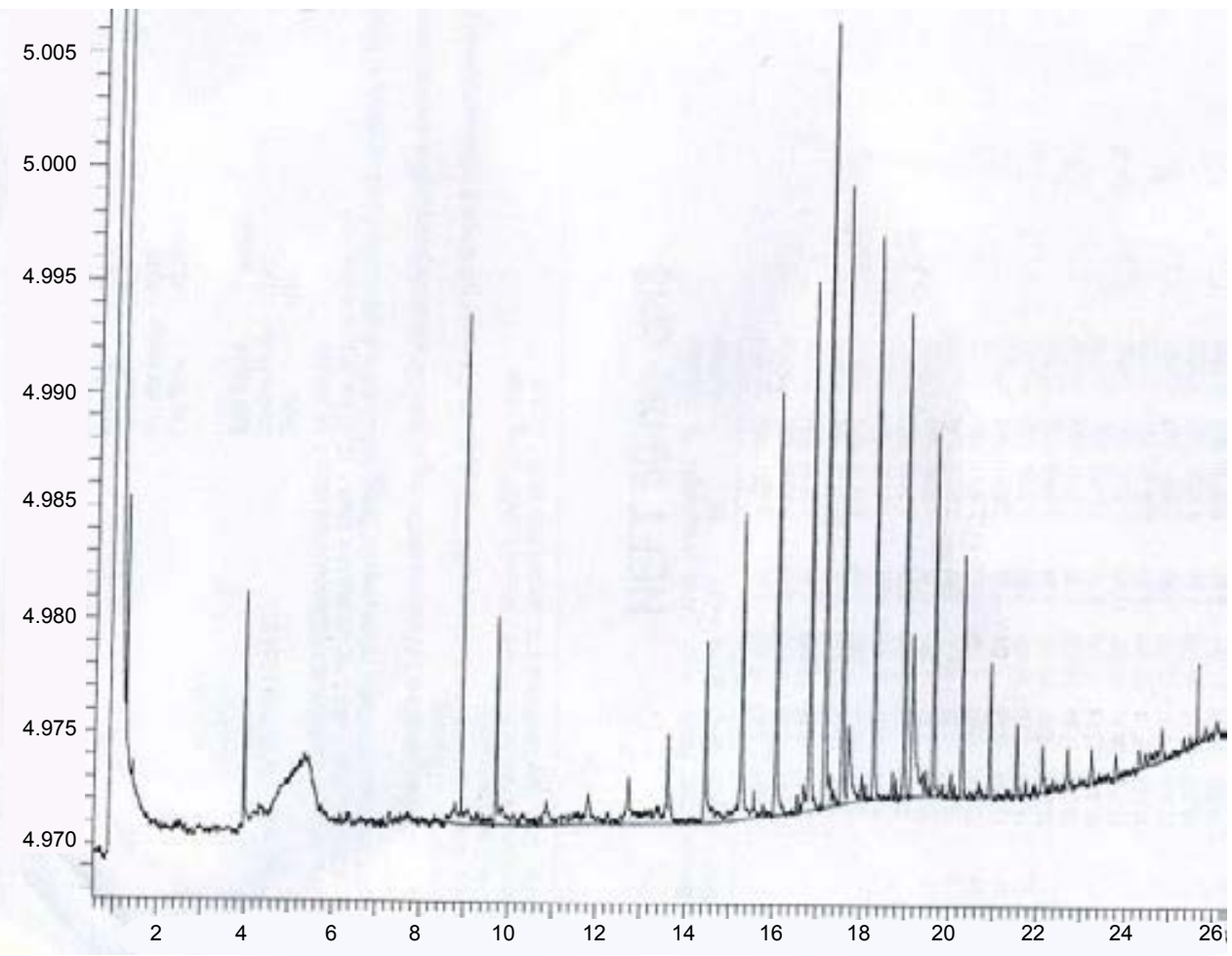

(b)

Figure 8: Chromatograms of asphaltenes separated varying ratio oil:precipitant: a) 1:10, b) 1:40. 
Citation: Tukhvatullina AZ, Barskaya EE, Kouryakov VN, Ganeeva YM, Yusupova TN, et al. (2013) Supramolecular Structures of Oil Systems as the Key to Regulation of Oil Behavior. J Pet Environ Biotechnol 4: 152. doi:10.4172/2157-7463.1000152

At a temperature of $60^{\circ} \mathrm{C}$ or higher there is a transition into the freely dispersed state with low values of the activation energy of viscous flow.

It was found that A1 asphaltenes contribute to the formation of the most stable bound-dispersed structure of oils, which greatly increases their viscosity. A2 asphaltenes disperse waxes greater than A1 asphaltenes, preventing the formation of the large crystals (Figure 5). Comparative analysis of the oil residue after distilling of the lowboiling fractions and maltenes with $\mathrm{A} 1$ asphaltenes it was shown that the stabilizing effect of resins in the absence of A2 asphaltenes is less pronounced.

Since the stable supramolecular structures are formed in heavy oils, it is necessary to apply technologies that affect directly to the core of the oil dispersed systems in order to reduce their viscosity. One of

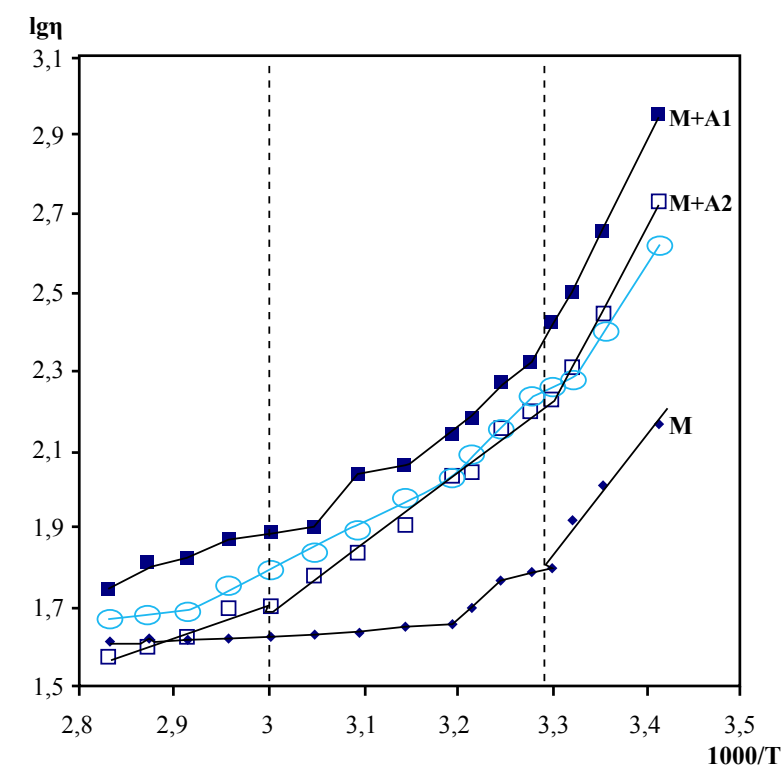

Figure 9: Viscosity-temperature dependence of the maltenes $(\mathrm{M})$ and model systems $(M+A 1, M+A 2)$.

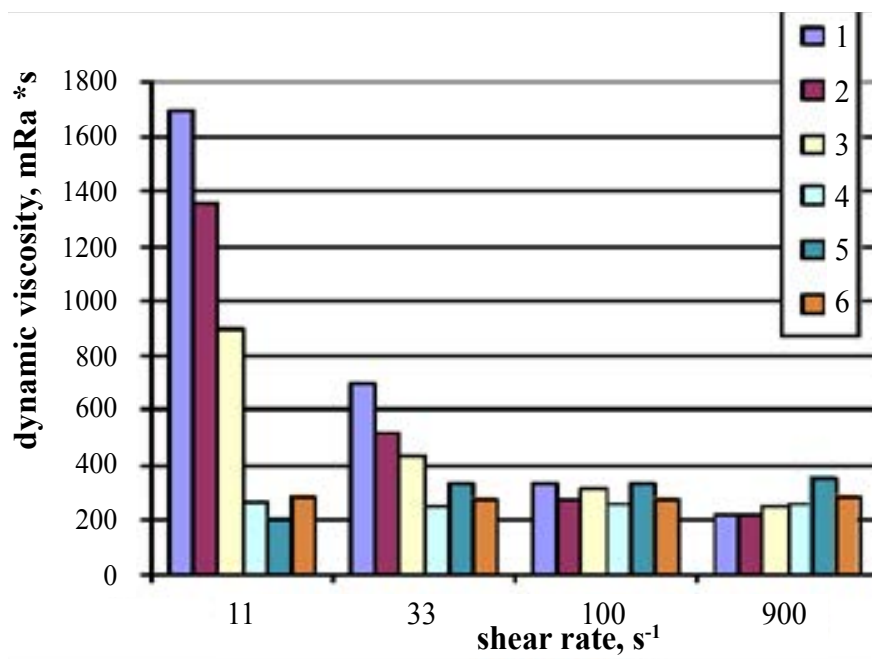

Figure 10: Change of the viscosity of the highly resinous oil before (1) and after sonication, depending on the intensity: $2-10 \mathrm{~W} / \mathrm{cm}^{2} ; 3-25 \mathrm{~W} / \mathrm{cm}^{2} ; 4-30 \mathrm{~W} /$ $\mathrm{cm}^{2} ; 5-50 \mathrm{~W} / \mathrm{cm}^{2} ; 6-100 \mathrm{~W} / \mathrm{cm}^{2}$

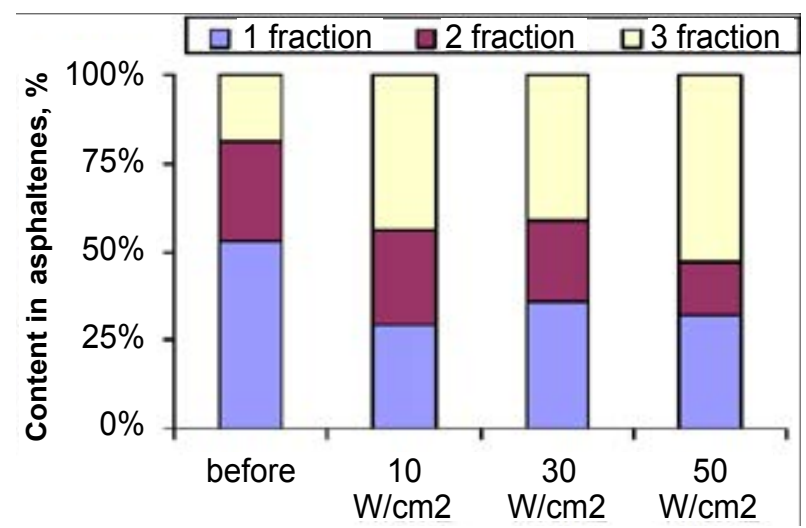

Figure 11: Change of the fractional composition of the asphaltenes from the highly resinous oil before and after sonication, depending on the intensity.

such technologies is the ultrasonic action [39-43]. The regularities of the influence of ultrasonic treatment on the structure of heavy oil with high content of resins were identified. It was found that ultrasound treatment leads to a decrease of oil viscosity (Figure 10), which is associated with changes in their dispersion structure [37].

The destruction of A1 and A2 asphaltene aggregates by sonication is proved by comparative data of asphaltenes fractionation from oil before and after sonication (Figure 11). The high content of A1 asphaltenes before ultrasound treatment can be explained by segregation of stable aggregates of A1 and A2 asphaltenes. After processing it is possible to isolate a more pure fraction of A1 asphaltenes according to EPR data (the content of stable free radicals: before sonication is 80 r.e., after sonication-more than 90 r.e.), the amount of which is markedly reduced. This effectively reduces the oil viscosity.

Asphaltenes are the indicators of many processes that occur in the reservoir. Previously [31] we have shown the possibility of using the gradient of asphaltenes, as well as their structure, to confirm the influx of deep light hydrocarbons in carbonate reservoirs.

Thus, all obtained results of investigation of structure formation processes will let regulate the macroscopic properties of heavy oils in the future and identify the processes occurring in the reservoir.

\section{Acknowledgements}

Authors would like to thank the RFBR Foundation for financial support (grants I.D. 12-03-00487 and research project No. 12-05-31345) and the Academy of Sciences of the Republic of Tatarstan (grant No. 03-47/2013 (G)).

\section{References}

1. Syunyaev RZ, Safieva RZ (2012) Oil disperse systems: softness, nanostructure hierarchy, phasic behavior. Georesources 3: 39-40.

2. Syunyaev ZI, Syunyaev RZ, Safieva RZ (1990) Oil disperse systems. Khimiya Moscow, Russia.

3. Safieva RZ (1998) Physical chemistry of crude oil: Psysicochemical foundations of petroleum refining technology. Khimiya, Moscow, Russia.

4. Tumanyan BP (2000) Scientific and Applied Aspects of the Theory of Petroleum Disperse Systems. Tekhnika, OOO TUMAgrupp, Moscow, Russia.

5. Mullins OC (2010) The Modified Yen Model. Energy Fuels 24: 2179-2207.

6. Mullins OC, Seifert DJ, Zuo JY, Zeybek M (2013) Clusters of Asphaltene Nanoaggregates Observed in Oilfield Reservoirs. Energy Fuels 27: 1752-1761.

7. Mullins OC, Betancourt SS, Cribbs ME, Dubost FX, Creek JL, et al. (2007) The colloidal structure of crude oil and the structure of oil reservoirs. Energy Fuels 21: $2785-2794$. 
Citation: Tukhvatullina AZ, Barskaya EE, Kouryakov VN, Ganeeva YM, Yusupova TN, et al. (2013) Supramolecular Structures of Oil Systems as the Key to Regulation of Oil Behavior. J Pet Environ Biotechnol 4: 152. doi:10.4172/2157-7463.1000152

8. Zuo JY, Mullins OC, Freed D, Zhang D, Dong C et al. (2011) Analysis of downhole asphaltene gradients in oil reservoirs with a new bimodal asphaltene distribution function. J Chem Eng Data 56: 1047-1058.

9. Mullins OC, Zuo JY, Freed DE, Elshahawi H, Cribbs ME, et al. (2010) Downhole fluid analysis coupled with novel asphaltene science for reservoir evaluation. $51^{\text {th }}$ Annual logging symposium, SPWLA, USA

10. Pacheco-Sanchez JH, Alvarez-Ramirez F, Martinez-Magadan JM (2004) Morphology of aggregated asphaltene structural models. Energy Fuels 18 1676-1686.

11. Rahimi H, Nazar ARS (2010) Asphaltene aggregates fractal restructuring model, a population balance approach. Energy Fuels 24: 1088-1093.

12. Tojima M, Suhara S, Imamura M, Furuta A (1998) Effect of heavy asphaltene on stability of residual oil. Catalysis Today 43: $347-351$

13. Acevedo S, Garcia LA (2012) Changes of diameter distribution with temperature measured for asphaltenes and their fractions A1 and A2. Impact of these measurements in colloidal and solubility issues of asphaltenes. Energy Fuels 26: $1814-1819$

14. Acevedo S, Castro A, Vasquez E, Marcano F, Ranaudo MA (2010) Investigation of Physical Chemistry Properties of Asphaltenes Using Solubility Parameters of Asphaltenes and Their Fractions A1 and A2. Energy Fuels 24: 5921-5933.

15. Marcano F, Flores R, Chirinos J, Ranaudo MA (2011) Distribution of Ni and V in A1 and A2 Asphaltene Fractions in Stable and Unstable Venezuelan Crude Oils. Energy Fuels 25: 2137-2141.

16. Buckley J (2012) Asphaltene deposition. Energy Fuels 26: 4086-4090.

17. Liao Z, Zhou H, Graciaa A, Chrostowska A, Creux P, et al. (2005) Adsorption/ occlusion characteristics of asphaltenes: some implication for asphaltene structural features. Energy Fuels 19: 180-186.

18. Derakhshesh M, Bergmann A, Gray MR (2013) Occlusion of polyaromatic compounds in asphaltene precipitates suggests porous nanoaggregates. Energy Fuels 27: 1748-1751.

19. Rogel E (2008) Molecular thermodynamic approach to the formation of mixed asphaltene-resin aggregates. Energy Fuels 22: 3922-3929.

20. Rogel E (2011) Effect of Inhibitors on Asphaltene Aggregation: A Theoretical Framework. Energy Fuels 25: 472-481.

21. Murgich J, Abanero JA (1999) Molecular recognition in aggregates formed by asphaltene and resin molecules from the Athabasca oil sand. Energy Fuels 13: $278-286$

22. Ortega-Rodriguez A, Cruz SA, Gil-Villegas A, Guevara-Rodrigues F, LiraGaleana C (2003) Molecular view of the asphaltene aggregation behavior in asphaltene-resin mixtures. Energy Fuels 17: 1100-1108.

23. Kriz P, Anderson SI (2005) Effect of asphaltenes on crude oil wax crystallization. Energy Fuels 19: 948-953.

24. Oh K, Deo M (2009) Characteristics of wax gel formation in the presence of asphaltenes. Energy Fuels 23: 1289-1293.

25. Garcia MC, Carbognani L (2001) Asphaltene-paraffin structural interactions Effect on crude oil stability. Energy Fuels 15: 1021-1027.

26. Ganeeva YM, Yusupova TN, Romanov GV (2011) Asphaltene nanoaggregates: structure, phase transitions and effect on petroleum systems. Russ Chem Rev 80: 1034-1050.

27. Akhmetov BR, Evdokimov IN, Eliseev NY (2002) Some features of the supramolecular structures in petroleum media. Chemistry and Technology of Fuels and Oils 4: 266-270.
28. Mohammadi AH, Richon D (2008) Estimating Onset of Precipitation of Dissolved Asphaltene in the Solution of Solvent + Precipitant Using Artificia Neural Network Technique. The Open Thermodynamics Journal 2: 82-88.

29. Castillo J, Gutierrez H, Ranaudo M, Villarroel O (2010) Measurement of the Refractive Index of Crude Oil and Asphaltene Solutions: Onset Flocculation Determination. Energy Fuels 24: 492-495.

30. Castillo J, Hung J, Fernandez A, Mujica V (2001) Nonlinear optical evidences of aggregation in asphaltene-toluene solutions. Fuel 80: 1239-1243.

31. Yusupova TN, Ganeeva YM, Tukhvatullina AZ, Romanov GV, Muslimov RKh, et al. (2012) Composition of Oils in Vereiskian and Bashkirian Carbonate Reservoirs of the Akanskoe Oilfield in the Republic of Tatarstan. Petroleum Chemistry 4: 215-220.

32. Yudin IK, Nikolaenko GL, Gorodetskii EE, Kosov VI, Melikyan VR, et al. (1998) Mechanisms of asphaltene aggregation in toluene-heptane mixtures. Journal of Petroleum Science and Engineering 20: 297-301.

33. Yudin IK, Anisimov MA (2006) Dynamic light scattering monitoring of asphaltene aggregation in crude oils and hydrocarbon solutions. Asphaltenes, Heavy Oils and Petroleomics. Springer, New York, USA.

34. Burya YG, Yudin IK, Dechabo VA, Kosov VI, Anisimov MA (2001) Lightscattering study of petroleum asphaltene aggregation. Appl Opt 40: 4028-4035.

35. Yusupova TN, Petrova LM, Mukhametshin RZ, Romanov GV, Foss TR, et al. (1999) Distribution and Composition of Organic Matter in Oil- and Bitumencotaining Rocks in Deposits of Different Ages. J Therm Anal Calorim 55: 99107.

36. http://u-sonic.ru/en/print/228

37. Barskaya EE, Tukhvatullina AZ, Ganeeva YM, Yusupova TN (2012) Influence of ultrasonication on the dispersed structure of the crude oils. $3^{\text {rd }}$ International Conference on Elastic wave effect on fluid in porous media. Moscow, Russia.

38. Ganeeva YM, Yusupova TN, Morozov VI, Romanov GV (2013) Selforganization behavior of asphaltene molecules in heavy oils with varying the oil: precipitant ratio. Petrol Chem 53: 220-224.

39. Kirillov LB, Pivovarova N, Vlasov GV, Milyaev AP, Radyuk RG (2011) Development of new methods for the preparation of primary hydrocarbon. Res Innov 5: 96-98.

40. Klokova TP, Volodin YA, Glagoleva OF (2006) Effect of ultrasound on the colloidal-disperse properties of petroleum systems. Chemistry and Technology of Fuels and Oils 42: 43-46.

41. Volkova GI, Prozorova IV, Anufriev RV, Yudina NV, Mullakaev MS, et al (2012) Ultrasonic treatment of oils for improvement of viscosity-temperature characteristics. Petroleum Refining and Petrochemistry 2: 3-6.

42. Loskutova YV, Prozorova IV, Yudina NV, Rikkonen SV (2004) Change in the rheological properties of high-paraffin petroleums under the action vibrojet magnetic activation. Journal of Engineering Physics and Thermophysics 77 1034-1039.

43. Guoxiang Y, Xiaoping L, Pingfang H, Xuan S (2010) Desalting and dewatering of crude oil in ultrasonic standing wave field. Journal of Petroleum Science and Engineering 70: 140-144. 